\title{
The Relationship Between Beauty and Metaphysics in the Theory of Saint Tomas Aquinas
}

\author{
Mahdi Amini
}

\begin{abstract}
Metaphysics and beauty are very important and challenging issues in philosophy that have been always noteworthy of philosophers. The relationship between these issues and the condition of these in philosophers's philosophical system is very different and various and every philosopher try to describe this in a specific way. It seems that there are very deep relationship between metaphysics and beauty in the philosophical system of philosophers that metaphysics is a fundamental subject in their philosophical system, because they explain their philosophical issue base on their metaphysical theory. Scholastic philosophers and philosophers of the middle Ages who were affected by Greek philosophy and lived in the Christian World are one group of that philosophers, however this relationship could be different. Saint Thomas Aquinas was a Catholic Priest in the Dominican Order and one of the most important medieval philosophers and theologians who have considered his theory base on metaphysics and theology. So, in this article I try by philosophical analysis method to show how metaphysics and beauty are connected in the philosophy of Thomas Aquinas. The results of this Article show that we cannot separate metaphysics and beauty in philosophy of Thomas Aquinas, so study on metaphysics of Thomas Aquinas is required as a prior condition for study on beauty.
\end{abstract}

Keywords: Tomas Aquinas, Metaphysics, God, Existence, beauty 